\title{
Conducting applied 'third-world' research in organizations - some problems and solutions
}

\author{
O. Harari \\ Mclaren College of Business, University of San Fransisco, California \\ D.T. Beaty* \\ Oraduate School of Business, University of Cape Town, Private Bag, Rondebosch, 7700 Republic of South Africa
}

Recoived 22 January 1987

\begin{abstract}
This article extends the argument put forward by Orpen (1985), that management researchers should consider the validity of the model used by applied research practitioners. Given the increasing complexity of issues affecting management and shop-floor workers in South Africa, this paper raises several problems of methodology that researchers applying the traditional 'scientific model' of research are likely to face. The authors draw on their personal experiences in conducting 'applied research', to suggest some solutions to the problems they have raised. The article concludes by suggesting that the 'scientific' model should be the foundation of applied research, but the architecture on top needs to be fitted to the messy and untidy complexities of real-wrorld data-gathering.
\end{abstract}

Hierdie artikel voer Orpen (1985) se argument dat bestuursnavorsers die geldigheid van die model wat toegepastebestuursnavorsers gebruik moet oorweeg, verder. In die lig van die toenemende kompleksiteit van sake wat bestuurders en klerke in Sujd-Afrika beinvloed, word probleme en metodes by toepassing van die tradlsionele 'wetenskaplike model', geopper. Die outeurs stel oplossings voor na aanleiding van hulle eic ondervinding tydens 'toegepaste navorsing'. Die artikel eindig met 'n voorstel dat die 'wetenskaplike model' as fondament moet dien vir toegepaste navorsing maar dat dit verder aangepas moet word om die morsige gekompliseerdhede van werklike inligtingversameling te huisves.

- To whom correspondence should be addressed

A recent article by Orpen (1985) highlighted the need for orthodox management science to consider the validity of a different model of research. He suggested that the 'scientific model' is often inappropriate for management research and should be substituted for one used by applied researchers. His reasoning was that genuine progress in improving our understanding of what needs to be done to manage organizations more efficiently and effectively, can best be achieved through the procedures used by applied researchers. Orpen (1985) contended that the research conducted by management practitioners and consultants is often 'messy and untidy' precisely because the real world these researchers seek to describe possesses these features. He suggested that the models used by applied researchers do more justice to the complexities of the 'real world', than the research which is conducted according to the 'ideal' described in the 'scientific model'.

It is our contention, that the issues facing South African managers and shop-floor workers have become increasingly volatile and complex because of the turmoil occurring within and outside the workplace. These realities which are often explosive in nature mean that organizational researchers who rely solely on ideal models of scientific research, will find themselves hamstrung by using traditional methodology that is impractical and sometimes even irrelevant. We concur along with Orpen (1985), that in order to capture meaningful data (particularly from black South African workers), management researchers need to adopt 'real world' methodologies that reflect the 'complex' features which make up an organization's people and environment. In fact, we would argue that management researchers should, as frequently as possible, combine qualitative research (interviews, structured or unstructured focus groups, face-to-face discussions) with quantitative research (controlled experimental designs, standardized instructions or scripts, carefully defined novel tasks) as a way of capturing more meaningful data within these real-world contexts.

This article will address itself to extending Orpen's (1985) argument and examining the practical implications of adopting an 'applied' model of research. That is, when conducting applied research among low-level shopfloor workers in a South African organization, what are the problems that a researcher who is trained in or desires to implement an orthodox 'scientific' method likely to face? Perhaps more important, what are the alternatives that the researcher can use to address the pitfalls that abound in working with this 'messy and untidy' world.

We propose that among some of the problems facing 'scientific' researchers who attempt to conduct 'applied' research, six practical issues stand out as salient, particularly within the South African context. Our comments in this paper are based on our several years of research experience in Africa, and our fellow faculty members' research experience in Central Asia and Latin America. We will use the terms 'First World' and 'Third World' throughout the article to describe the populations we are discussing. For purposes of clarity for the South African 
context, we will define 'first world' as 'white' South Africans and 'third world' as 'black' South Africans.

\section{Problems In applying the traditional paradigm to} third-world particlpants.

Many third-world research participants are completely unfamiliar with the notion of 'scientific research'. Sterile research settings like carefully arranged tables, chairs, questionnaires, carefully defined novel tasks to perform standardized instructions, scripts, formally structured interviews, etc. are an alien experience. Likewise, detached, cool and polite professional researchers who quickly 'get down to business' and who create a formal and precise task-oriented environment are also an alien experience. These alien experiences often provoke anxiety, insecurity, obsequiousness, withdrawal, or hostility. To some extent, these reactions are often experienced even by first-world participants (Adair, 1973; Argyris, 1968), but we have found that they are highly compounded among third-world participants.

Many third-world participants are fearful, suspicious, or cynical about the motives of first-world researchers. From their perspective, the research may have 'masterslave', 'colonialist' or 'oppressive' overtones. Our experiences in Africa have shown us that many third-world individuals are sensitive to nuances that suggest hidden motives which are exploitative. The rather precise, detached, formal and benevolantly autocratic ambiance of a typical first-world research environment (Argyris, 1968) often appears to do just that.

Consistent with other research (e.g. Hofstede, 1983; McClelland, 1971), we have found that most third-world participants emphasize values such as openness, warmth, and collaboration. When the researcher does not demonstrate these qualities, participants often withdraw psychologically from the research or attempt to undermine the research process by giving erroneous responses.

Language is an acute problem. First of all, continents like Asia, Africa, and Latin America have a myriad of languages and dialects. Africa alone has over 2000 languages, and, as we found, it is quite possible to sample a particular group of respondents whose members may speak a different primary language. We also found that different languages can often reflect ethnic or tribal differences - or even hostilities. Secondly, researcherparticipant language differences are greater in thirdworld contexts than in first-world contexts. That is, the differences between English and French, for example, are fewer than those between English and Zulu because the latter involves more subtleties that are difficult to translate on an exact word-to-word basis. The critical impact of these subtleties has been documented in other cross-cultural social science reports. Sometimes they verge on the ludicrous. For example, Barley (1985), an Englishman researching the Dowayos in the Cameroons, Africa, noted that the language has four tones which differentially affect meaning. In one case, Barley tried to say to an important Dowayo, 'I am cooking some meat' and his statement came out as 'I am copulating with the blacksmith'. Even written translations are potentially dangerous in the third-world, as Pepsi Cola learned when its ad 'Come alive with Pepsi' was translated into Mandarin as 'Pepsi brings your ancestors back from the dead' (Solomon, 1978).

Education and literacy are important issues. In firstworld settings, the researcher assumes that participants can comprehend simple verbal or written instructions and that they can fill out a simple questionnaire. These are often unwarranted assumptions among third-world participants, even among those that have had schooling or who appear to understand what is required. This problem is particularly noticeable when conducting research among South African black shop-floor workers, the majority of whom are semiliterate.

The researcher's stereotypes and expectations have a subtle but pervasive effect on the research. This is true even in first-world settings (Insel \& Jacobson, 1975; Livingston, 1969). However, in third-world settings we have found that it is an extremely salient issue. Researchers may come into the process holding stereotypes of the participants to the researcher. The stereotypes may be positive or negative, but the researcher who uncritically accepts these stereotypes, or rigidly holds on the particular expectations, is truly walking into a minefield in third-world settings. The fact that the researcher is usually from a different culture and race increases both the likelihood and danger of these preconceptions.

These are just some of the critical factors that can easily undermine a researcher using a traditional 'scientific' paradigm in organizational settings and real-world experiences. We confess that we found this out through the school of hard knocks. Our initial research endeavours with third-world participants resulted in frustration and inefficiency, unusable data, resistance and just minimal compliance among participants, chaos in data collection, and, in a couple of instances, near violence among participants of different ethnic backgrounds. We therefore wish to share with the reader some of the steps we learned which we found so necessary to follow in conducting third-world research. These steps appear to be simple - perhaps even simplistic. Yet we found them to be essential, often overlooked, and often very difficult to actually execute.

\section{Strategles and Suggestions}

Before even developing a methodology, we found that it helps the researcher to study the culture, people, and region which he or she will sample. This includes the history, political climate, prevailing values and attitudes, ethnic differences, and geography. Barrett \& Bass (1976) also suggested that cross-cultural researchers study the socialization patterns, economics, and organizational dynamics of the host country. Otherwise, a researcher may wind up in a rueful situation such as the one experienced by Barley (1985) with the Dowayos. He used a youthful interpreter in a culture contemptuous of youth, and he used females in his sample, an outrageously stupid act according to the (dominant) males. We have found that frequently the first-world researcher does not even realize the gaffes and misinterpretations 
that occur as a result of cultural ignorance (see also Hall \& Whyte, 1960; Schemerhorn, Hunt \& Osborn, 1985).

Prior to conducting the actual research and data gathering, the researcher should carry out what we call RBWA, or 'research by wandering around'. This concept is a spinoff on what Peters \& Waterman (1982) refer to as MBWA, or 'management by wandering around'. Their rationale for MBWA is that managers need to get out of their offices and get back in touch with the needs and wants of customers and employees. We believe, along with Peters \& Watermann (1982), that the same issues apply to researchers. Too often, investigators communicate only with senior managers and get only a perfunctory tour of the organization. Sometimes they simply send assistants to gather the data. We feel that this is counterproductive in first-world contexts but potentially lethal in third-world contexts. We propose that the investigator needs to spend quality time visiting the company, observing, and talking to members of the participant pool in order to get a real feel for the participants. We have found that through preliminary RBWA, we can change erroneous stereotypes and expectations, reduce cultural barriers, anticipate problems, add or modify issues to investigate, and respond adequately to unanticipated obstacles.

The researcher must be more open with the participants in third-world than in first-world contexts. Minimally, the researcher must insist to management that there will be no deliberate misleading or deception. We also ask senior managers how the research will benefit participants. We also strongly urge management to share the final research results with participants. We have found that these steps are useful in setting a stage for candor in third-world contexts, where candor between management and nonmanagement may not exist. However, once the stage is set, more work must be done.

Prior to data collection, we reassure participants that their jobs are not in jeopardy, regardless of their responses. In fact, we spend time explaining the concept of 'there are no "right" answers'. We also make sure to reassure participants that there will be a discussion of the research after they complete the task. Finally, though this may sound odd, the researcher, depending on the company or country, may need to convey to participants that he/she is not a spy or tool of management, and that they should be candid in their responses without fear of political or management reprisal.

We have found that it is useful to speak with 'informal leaders' of employees prior to data collection. Reassuring informal leaders and gaining their support for the proposed research can be a tremendous advantage. It is critical however, that the leaders are not management's 'leaders' but rather the employees' real informal leaders. If management chooses the leaders, the researcher must make it clear that the 'leaders' should have influence and credibility with participants, even if management doesn't particularly like the ones chosen by the participants.

Extensive pretesting of materials and procedure is vital. All translations of instructions and written materials should be checked and rechecked by individuals (note plural) from the same community of the subjects who can identify not only errors but also idioms and nuances that are unique to that particular group. We have used the following strategy: First, we obtain translations from linguistic experts. Then assuming we are not in the same locale as our research sample, we send the translations to the organization in which we will conduct the study. We ask our contact within the organization to informally try out the materials with people in the area (perhaps even in the organization) to check for accuracy and ease of understanding. Simultaneously, we conduct small informal focus groups; each group consists of up to five individuals of the same culture, income level, social status, and ethnic background as our future subjects. In some groups we review the materials and procedures that we intend to use. In other groups we actually go through the entire research procedure with them and then invite discussion. If we cannot organize these groups where we are located, we ask our in-house contact to organize them.

In all instances where the researcher's primary language is different from the primary language of participants (almost always the case in third-world contexts), an interpreter should be used. The interpreter cannot simply be a passive appendage of the research project; he or she is critical to its success and should be an active key player - almost a partner - in the process. We believe this action is important because the interpreter will become the researcher's major link to the very different world of the participants. The interpreter also personifies the research to the participants.

The interpreter should obviously be fluent in both languages in question, and should be of the same cultural and racial background as the participants. The interpreter should, whenever possible, be a member of the target organization; ideally, he or she should be known to the participants and respected by them as an informal leader. He should have the education to understand the research content and aims. He should understand the importance of the research and the reasons for cooperating with the researcher; these latter requirements are dependent primarily on the researcher's candor and integrity in 'selling' the research. Management should understand these criteria if they pick the interpreter.

The researcher should meet with the interpreter before data collection, ideally even before the research is publicized in the company. In an informal and relaxed environment, the researcher should explain to the interpreter what the research is about and what his/her role is. We go over the complete methodology with the interpreter. We ask for his/her critique, comments, and suggestions regarding materials and procedure (for this reason we prefer to use the interpreter as early as the pretesting phase). We ask the interpreter for tips on 'selling' the research to subjects. We ask him for 'do's' and 'don'ts' in terms of our behaviour and choice of words. We have found, for example, that a straightforward business style of communication can be perceived as overly blunt and aggressive. We have found that appropriate 'personal space' between researcher and subject can vary. We have found that there are certain terms or subjects that should, and should not, be 
mentioned by the researcher. We have learned the importance of specific non-verbal communication messages.

Obviously, a complete dry-run practice session with the interpreter should occur prior to the actual data collection. However, during data collection, the interpreter must also be encouraged to take the initiative and answer subjects' questions, rephrase the researcher's comments, note who is having problems understanding instructions or carrying out the task, and help those subjects who need it. The interpreter should also be encouraged to privately voice his comments and suggestions to the researcher during the data-collection phase. This is one reason why the interpreter must really understand and support the research project; he/she cannot simply be a passive conduit.

In situations where participants have a working knowledge of English, we still found an interpreter useful to occasionally explain and summarize concepts to participants (as well as to teach us about cultural do's and don'ts). In the more common occurrence where participants have little knowledge of English, the interpreter can and should be as active and verbal as the researchers.

The rule of thumb: Always have an interpreter when the primary languages of researcher and participants differ - even if 'everyone' assures you that there is no need for one! We have concluded that a great interpreter is worth his/her weight in gold.

When gathering data, groups of subjects should be kept small: 20 maximum, even with questionnaire-based research. Through trial and error, we have found that this is absolutely necessary for reduction of tension, for increased subject commitment, and for our ability to see who is not understanding instructions, who is sceptical, who is resistant, etc. Twenty may appear 'inefficient', but we have found that economies of scale (e.g. putting 50-100 people in a room to complete a questionnaire) work only in theory. Many samplings of small groups are much more likely to elicit valid data than is the use of a few large groups.

When gathering data, the researcher should keep groups as homogeneous as possible. Blue-collar and nonsupervisory employees should not be sampled in the same group with supervisors or managers. Hierarchy is more fixed and rigid in many third-world contexts. In addition, workers are often a different race from managers, and hence racial overtones can emerge in a mixed group.

Groups should also be separated along primary cultural, language and ethnic lines. Accurate communication between researcher and subjects is much more likely to occur when the participants (and interpreter) are a homogeneous group. We have found that cultural and language heterogeneity can lead to disorder, bad feelings, unnecessary interruptions (e.g. translating in more than one primary language), petty rivalries, and even the danger of fistfights. We have also learned that top management is not necessarily correct when they assure the researcher that groups can be heterogeneous because supposedly all segments of the workforce work 'perfectly' with each other. We have found that sticking to our rule - keep the groups homogeneous - has increased our success in the research process.

Finally, when more than one type of cultural or language group exists, more than one interpreter has to be used, and 'informal leaders' must include representatives of each group.

When actually conducting the research (especially in the data-collection phase) we have found it is important to keep organizational members higher up in the hierachy out of sight. In first-world research, it may be useful when 'higher ups' are visible because their pres. ence shows their support and enhances the credibility of the research. In third-world settings, however, this 'visibility' can just as easily lead to anxiety, intimidation, suspicion or hostility on the part of the participants.

Moreover, this 'visibility' can easily reinforce a perception that the researcher is simply acting as a tool of management. Hence, for example, when sampling nonmanagers, we tell managers to stay out of the research room and not to interrupt at any time, even if their motives are truly benign. More than once we have had to ask executives who had unexpectedly 'dropped in', were oblivious to the increase in tension in the room, and who wouldn't take our hints to leave. At all these times, incidentally, we apologized to the participants for the executive's entrance after he had left the room.

Consistent with our earlier comments about candor, the researcher must be more personally open and selfrevealing in third-world contexts. We have noted that many third-world participants feel uncomfortable about 'immediately getting down to business'. Hence, we start by spending five to ten minutes chatting and joking with each group. We may talk briefly about ourselves, our work, our cities of residence, our families. We actively solicit dialogue in order to establish rapport with the participants.

We have found that informality is important in breaking down cultural walls. We are very informal: no suits or ties (unless participants wear them), no standing behind podiums or tables (we sit on a table or stand in front of it), and no reading scripts (we talk directly to participants). Prior to the meeting, we ask our interpreter to teach us basic words of introduction and politeness. Our experiences parallel those of American businessmen who find that even their poor attempts at trying-out the language yields 'fantastic results' (Munz, 1982). Sometimes we have fouled up the participants' language so badly that laughing along with the participants, we have asked them for the correct pronounciation or vocabulary, and repeated it, usually with more laughter. Little events like these are wonderful in breaking down suspicion and tension.

When participant literacy skills are marginal (as is often the case), the researcher must emphasize verbal instructions and use exaggeratedly simple language. Visual aids are also useful. In our questionnaire research, for example, we usually make a duplicate copy of both the questionnaire and answer form and put both on a transparency which is shown on an overhead projector. We then actually complete $a$ form in front of participants on 
the transparency, constantly repeating that this is only an example and not the 'correct' way. We also make liberal use of poster paper and blackboard for illustrating the concepts and try to keep written materials to the minimum.

After we have collected data from each group of participants, we have found it helpful for the researcher to address any questions and concerns, and provide brief explanations regarding the nature, scope, and purposes of the research. Common sense will dictate how detailed the explanation should be. But we believe it is imperative that some debriefing take place immediately after data gathering. Generally, we adopt a looser, more informal style in debriefing than in the data-gathering phase. Finally, we thank participants profusely for their cooperation and ask them not to discuss the details of the research with future participants until the entire project is completed. Our rule of thumb is: Do not herd participants out quickly after data collection with the promise of future debriefing; spend time with them to reassure them, to compliment them, to thank them, and to give them a sense of closure. We have found that taking the five to ten minutes to do this is critical for maintaining our credibility and their goodwill.

\section{Conclusions}

Methodological procedures that are taken for granted in 'scientific' settings need to be tailored to conditions more specific to third-world conditions and cultures. In and of itself, this is not a radical suggestion. Wachtel (1980), for example, described typical research models as 'far too monolithic' (p. 400). Barrett \& Bass (1976) noted that the 'scientific' researcher typically 'looks at both practical problems and research and theoretical issues from a relatively narrow perspective' (p. 1674). They stated that 'our concepts, structures, and models may shift from culture to culture' (p. 1675) and urged the researcher to carefully consider cultural differences when conducting applied research. We believe that these comments are especially germane for those conducting research in South African and third-world contexts.

In this article, we have presented some issues, pitfalls, strategies, and tips for the applied researcher who wishes to capture meaningful 'real world' data. At no time have we argued for the traditional foundations of rigorous research to be scrapped. Indeed, the foundation remains 'traditional', but we believe the architecture on top needs to be fitted to the messy and untidy complexities of the real world of management research. We suggest that the applied researcher should think a little differently when working in applied management and organizational contexts in the Third World.

We hope that this article will help equip the researcher trained in a 'scientific model' with a broader range of methodological tools. We have found that by adopting the ideas and actions suggested in this article, we have markedly reduced our frustrations and considerably enhanced the reliability and validity of our findings. Moreover, we have enjoyed the research process more, and have found ourselves much more receptive to the beauty and subtlety of other people and cultures.

\section{References}

Adair. D.G. 1983. The hurnan subject. Boston: Little, Brown.

Argyris, C. 1968. The unintended consequences of rigorous research, Psychol. Bull., vol. 70, 185-197.

Barley, N. 1985. Adventures in a mud hut. New York: Vanguard.

Barret, G.V. \& Bass, B.M. 1976. Cross-cultural issues in industrial and organizational psychology. In: Handbook of incustrial and organizational psychology. M. Dunnette, Ch. ed., Chicago: Rand-McNally 1639-1686.

Hall, T.T. \& Whyte, W.F. 1960. Intercultural communication: A guide to men of action. Human Organization. Spring, 1.

Hofstede, G. 1983. The cultural relativity of organizational practices and theories. J. Intern. Bus. Studies, Fall, 75-89.

Insel, P.M. \& Jacobson, L.F. 1975. What do you expect? An enquiry into self-fulfilling prophecies. Menlo Park: Cummings.

Livingston, J.S. 1969. Pygmalion in management. Harv. Bus. Rev. , 47, 81-89.

McClelland, D. 1971. Motivational trends in society. Morristown: General Learning Press.

Munz, M. 28 June 1982. Companies find cultural pitfalls abound in foreign-market deals. San Fransisco Bus. J., 1-5.

Orpen. C. 1985. Applied research in management. S. Afr. J. Bus. Mgmnt, 16, 116-118.

Peters, T.J. \& Waterman, R. 1982. In search of excellence. New York: Harper \& Row.

Schemerhorn, J.R., Hunt, J.G. \& Osborn, R.N. 1985. Managing organizational behaviour, (2nd ed.), New York: Wiley.

Solomon, B. 1978. Gross national products. Neu Times, June 26, 58-64.

Wachtel, P.L. 1980. Investigation and its discontents. Am. Psychol., 35, 5, 399-408. 